\title{
Clinical Presentation and Management of Brain Metastasis in a Sample of Iraqi Patients
}

\author{
Mustafa Jarullah Neamah ${ }^{1}$, Ihssan S Nema ${ }^{2 *}$ and Liwa Abdullah Ali ${ }^{1}$ \\ ${ }^{1}$ Department of neurosurgery-AL-Emamian alKadhimian Medical City-Baghdad, Iraq \\ ${ }^{2}$ Department of Surgery, College of medicine- Al-Nahrain University, Baghdad, Iraq \\ *Corresponding author: Ihssan S Nema, Department of Surgery, College of medicine- Al-Nahrain, University, Baghdad, Iraq \\ To Cite This Article: Ihssan S Nema. Clinical Presentation and Management of Brain Metastasis in a Sample of Iraqi Patients. Am J Biomed Sci \& \\ Res. 2019 - 5(4). AJBSR.MS.ID.000936. DOI: 10.34297/AJBSR.2019.05.000936.
}

Received: 䟧 September 15, 2019; Published: 眥 October 01, 2019

\section{Introduction}

Brain metastases are neoplasms that originate in tissues outside the brain and spread secondarily to involve the brain [1] This may result either from direct local extension of the primary growth, or from blood born metastases [2]. The intracranial compartment is a common site of metastatic cancer. Between 20 and $40 \%$ of patients with systemic cancer developed brain metastasis. Such metastasis can be extra axial in nature (e.g. involving the dura and subdural space, or leptomeninges and subarchnoid space), but most commonly they occur within the brain parenchyma [3]. However, the importance of intracranial metastases is not primarily due to its frequent occurrence, but to the fact that manifestations of metastases affecting the brain are usually more overt and disabling and if untreated tend to be rapidly lethal if compared to metastases to other organs such as lung and liver (in which the incidence of metastases is even higher).

At present, the prevalence of brain metastases among cancer patients is estimated to be $20-40 \%$. Metastatic brain tumor derived from cancer of lung are the most common type, making up 40-60\% of the total, followed by those derived from breast cancers (15$20 \%$ ) and melanoma (10-20\%) depending whether the data come from a clinical or autopsy series. Colorectal and renal cell carcinoma account for $5-10 \%$ each. These five sources are responsible for most cerebral metastasis. Melanoma has the highest propensity to spread to brain, but is less well represented than lung cancer in large series because of the much greater incidence of lung cancer in the general population. In patients younger than 21 years of age, brain metastases arise most often from sarcomas (Ostoegenic sarcoma, Rhabdomyosarcoma, and Ewing's sarcoma) and from germ cell tumors (e.g. neuroblastoma).

\section{Patient and Methods}

This is a prospective study of (25) patients of metastatic brain tumors who were admitted to the Neurosurgical Hospital of Baghdad in the period between January 2004 and January 2007. The patients included in this study are those who had an operation for intracranial lesion and had a histopathological proof to be a metastatic tumor, or those who had no operation to the intracranial lesion,but have a histopathological proof of primary lesion. Patients with unknown primary lesion and a clinical and radiological suspension of having an intracranial metastasis and managed depending on this suspension were excluded from the study.

The data were collected from the patient in the hospital mentioned above including the descriptive data, the neurological presentation, and the previous history of the primary lesion, the important investigations, the details of the operation and the histopathologieal report. Blood samples were obtained for all patients to test the complete blood picture (CBP) including the $\mathrm{Hb}$, PCV, and ESR [4,5] Blood biochemical studies were done including random blood sugar (RBS) and blood urea for all the patients, serum creatinine for all patients, and liver function tests for all patients.

\section{Skull X ray}

In both the postero-anterior and lateral views, looking for any raised intracranial pressure (ICP) e.g. demineralization of the dorsum sellae; sign of mass effect e.g. shift of calcified pineal body to one side; or any abnormal calcifications [6,7].

\section{Chest X ray}

Postero-anterior views were taken for all patients looking for any primary lesions that could originate from the chest.

\section{Brain C-T scan}

Done for all patients searching for a primary lesion or a secondary deposit in one of the abdominal Organs. 
The features studied include:

a) Multiplicity, which means single or multiple metastases, could be found.

b) Site of metastases.

c) Tumor density (compared to the brain).

d) Perifocal edema and mass effect.

e) Associated hydrocephalus.

f) Presence of calcification.

MRI pictures were obtained from the records of the patients.

\section{Management}

\section{Medical}

All the patients received dexamethasone $4 \mathrm{mg} 6$ hourly IV after the CT diagnosis even for those who had no operation for the intracranial lesion. Carbamazepine in a dose of $200 \mathrm{mg} \mathrm{2-4}$ times daily was used in 13 patients, 6 of them had seizure at time of presentation, and the other 4 were given the Carbamazepine prophylactically in the preoperative period $[8,9]$.

\section{Surgical}

Surgery was done for 13 patients. The type of the operative intervention was determined according to the site, size of the tumor, age of the patients, and his medical and general conditions regarding fitness for surgery and anesthesia. The management of the primary lesion also played a role in the management of the intracranial metastasis. All the 13 patients were operated under the general anesthesia (GA). The surgery was burr-hole biopsy, craniotomy, or a posterior fossa craniectomy. The last two were either with total removal of the tumor (macroscopically completely removed), $[10,11]$ or subtotal removal (significant part left because it was inaccessible or invading important structures). The cystic component of the tumor was aspirated in those tumors that are not removed totally to achieve a better decompression. The pathological specimens were preserved and send for the histopathological study to confirm the diagnosis of metastasis.

\section{Radiotherapy}

All of our patients in this study received radiotherapy for the intracranial lesion after histopathologieal diagnosis of the secondary lesion by operation in 13 patients, or by radiological diagnosis in-patients with a known primary lesion. The radiation was in the form of whole brain radiotherapy (WBRT) $[12,13]$ in a dose ranging from 2000 - $4000 \mathrm{rad}$ in 2-4week.

\section{Result}

\section{Incidence}

During the period of study (from Jan.2004 to Jan. 2007), the incidence of metastatic brain tumors compared to other primary brain tumors was found to be $15 \%$.

\section{Gender}

There were 15(60\%) male patients and 10(40\%) female patients in this study. The male: female ratio was (1.5:1) (Figure 1).

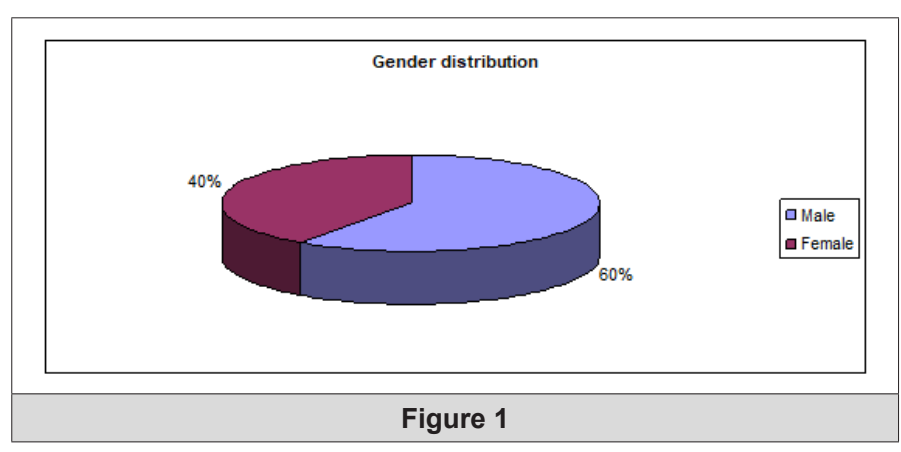

Age

The age range was 30-70 years. The largest number of patients was in the age group (40-49 years). Male preponderance is present in all age groups except in the 2nd group (40-49 years) in which number of female patients is more. (Table 1), See (Figure 2).

\begin{tabular}{|c|c|c|c|c|c|}
\hline \multicolumn{2}{|c|}{ Sex \Age group } & $\begin{array}{l}30-39 \\
\text { Years }\end{array}$ & $\begin{array}{l}40-49 \\
\text { Years }\end{array}$ & $\begin{array}{l}\text { 50-59 } \\
\text { Years }\end{array}$ & $\begin{array}{l}>-60 \\
\text { Years }\end{array}$ \\
\hline \multirow[t]{2}{*}{ Males } & No. & 1 & 4 & 6 & 4 \\
\hline & $\%$ & 4 & 16 & 24 & 16 \\
\hline \multirow[t]{2}{*}{ Females } & No. & 1 & 5 & 2 & 2 \\
\hline & $\%$ & 4 & 20 & 8 & 8 \\
\hline \multirow[t]{2}{*}{ Total } & No. & 2 & 9 & 8 & 6 \\
\hline & $\%$ & 8 & 36 & 32 & 24 \\
\hline
\end{tabular}

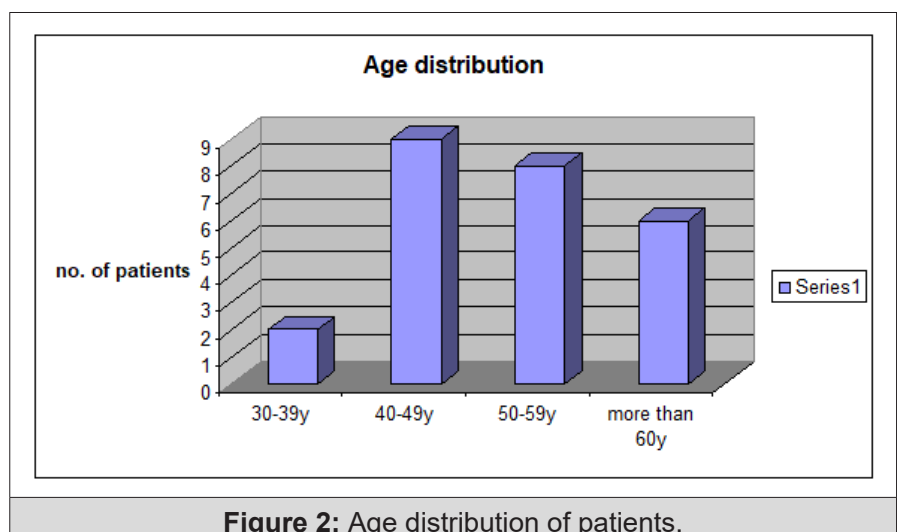

\section{Presenting Symptoms}

\section{Headache}

Was the presenting symptom in 12 patients (40\%), 7 were males and 5 were females. It was of moderate severity in 7 patients and markedly severe in 5 patients [14,15]. The headache was generalized in 9 patients, occipital in 4 patients, and bifrontal in 2 patients.

\section{Focal weakness}

Was the presenting symptom of 7 patients (28\%), 4 of them were males and 3 were females. The weakness was in form of right- 
sided weakness in 3 cases, left-sided weakness in 2 cases, [16,17] and right-sided facial weakness in one case.

\section{Fit}

Was the presenting symptom in 2 patients ( $8 \%$ ), 1 was males and 1 was females. The fit was generalized in both cases.

\section{Deterioration of consciousness}

Was the presenting symptom in 2 patients ( $8 \%$ ) were males. It was progressive.

Unsteady of gait: was the presenting symptom of 1 patient (4\%) was female.

Double vision: was the presenting symptom of 1 patients (4\%) was male.

\section{Duration of the Presenting Symptoms}

This is the period from the appearance of the presenting complaint to the date of the medical consultation. The range was from few hours to more than a year. The onset was regarded to be sudden if the $[18,19]$ duration was less than 1 month, and this is seen in 12 patients ( $48 \%$ ) (Table 2 \& Figure 3 ).

\begin{tabular}{|c|c|c|}
\hline \multicolumn{2}{|l|}{ Table 2: Duration of presenting symptoms. } \\
\hline Duration of the presenting symptom & No. of patients & $\mathbf{\%}$ \\
\hline Under 1 month (sudden) & 12 & 48 \\
\hline 1-3 months & 7 & 28 \\
\hline 3-6 months & 4 & 16 \\
\hline Up to 1 year & 2 & 8 \\
\hline
\end{tabular}

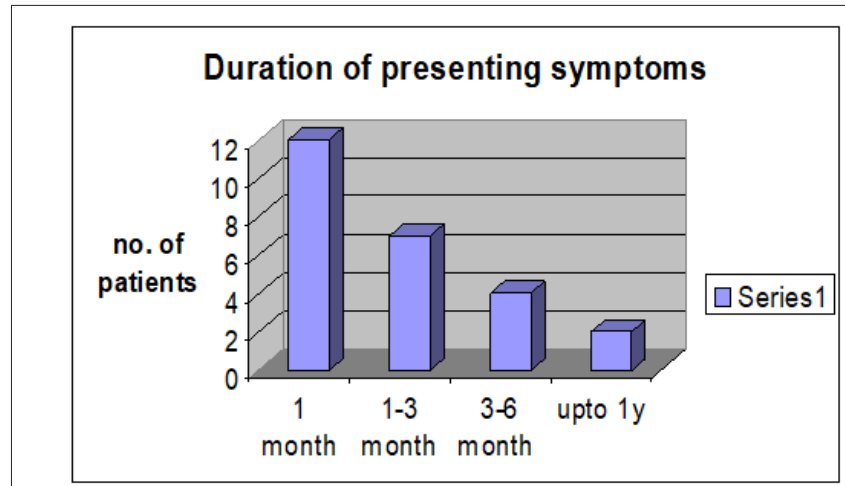

Figure 3: Duration of presenting symptoms.

\section{Interval between diagnosis of primary tumor and cerebral metastasis}

This is an important aspect in the management of patients with cerebral metastasis. It is the time elapsing from the detection of the primary tumor until the occurrence of neurological signs. In this study we found 15 patients $(60 \%)$ with a diagnosed primary tumor. Six patients of them presented in the first 6 months after the diagnosis of the primary tumor, 4 patients presented after 6 months - years, 4 patients presented after 1-5years, and only 1 patient presented after more than 5 years (it was a transitional cell carcinoma of the bladder). This is shown in the (Table 3).

\begin{tabular}{|c|c|c|c|c|}
\hline \multicolumn{6}{|c|}{ Table 3: Interval between diagnosis of primary tumor and metastasis: } \\
\hline $\begin{array}{c}\text { Duration } \backslash \\
\text { Primary }\end{array}$ & $\begin{array}{c}\mathbf{0 - 6} \\
\text { months }\end{array}$ & $\begin{array}{c}\mathbf{6 m o n t l h s -} \\
\text { year }\end{array}$ & $\mathbf{1 - 5}$ years & $>\mathbf{5}$ years \\
\hline Lung & 4 & 1 & 2 & \\
\hline Breast & 1 & 2 & 2 & \\
\hline Bladder & & & & 1 \\
\hline Lymphoma & 1 & & & \\
\hline Colon & & 1 & & \\
\hline
\end{tabular}

\section{Primary site}

In this study of 25 patients, the primary origin of the cerebral metastases was known in 15 patients (60\%), and unknown in 15 patients (40\%). This is distributed as shown in the (Table $4 \&$ Figure 4).

\begin{tabular}{|c|c|c|}
\hline \multicolumn{3}{|c|}{ Table 4: Origin of metastatic brain tumors. } \\
\hline Primary site & No. of patients & $\%$ \\
\hline Lung & 7 & 28 \\
\hline Breast & 5 & 20 \\
\hline Bladder & 1 & 4 \\
\hline Lymphatic system & 1 & 4 \\
\hline Colon & 1 & 4 \\
\hline Unknown & 10 & 40 \\
\hline
\end{tabular}

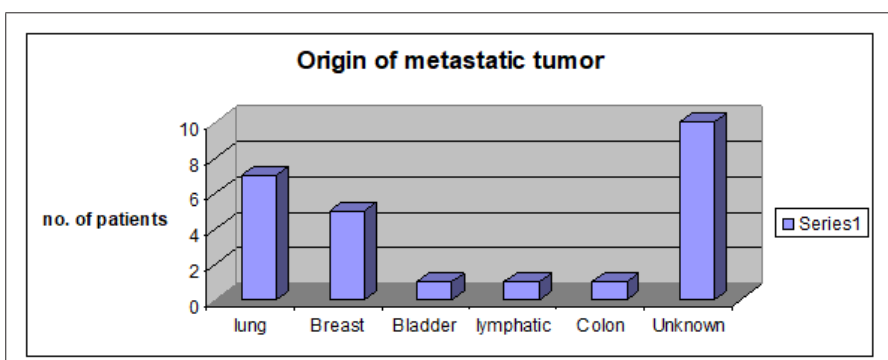

Figure 4: Origin of metastatic tumor

\section{Symptoms}

They are summarized in (Table 5 \& Figure 5).

\begin{tabular}{|c|c|c|}
\hline \multicolumn{2}{|l|}{ Table 5: Presenting symptoms. } \\
\hline Symptom & No. & $\%$ \\
\hline Headache & 20 & 80 \\
\hline $\begin{array}{c}\text { Nausea/Vomiting } \\
\text { Nausea/Vomiting }\end{array}$ & 15 & 60 \\
\hline Focal Weakness & 14 & 56 \\
\hline Unsteady Gait & 10 & 40 \\
\hline Seizures & 9 & 36 \\
\hline Blurred Vision & 7 & 28 \\
\hline $\begin{array}{c}\text { Disturbed } \\
\text { Consciousness }\end{array}$ & 7 & 28 \\
\hline Speech difficulty & 4 & 16 \\
\hline Behavioral changes & 4 & 16 \\
\hline Dysphasia & 3 & 12 \\
\hline Double Vision & 2 & 8 \\
\hline Numbness & 1 & 4 \\
\hline
\end{tabular}




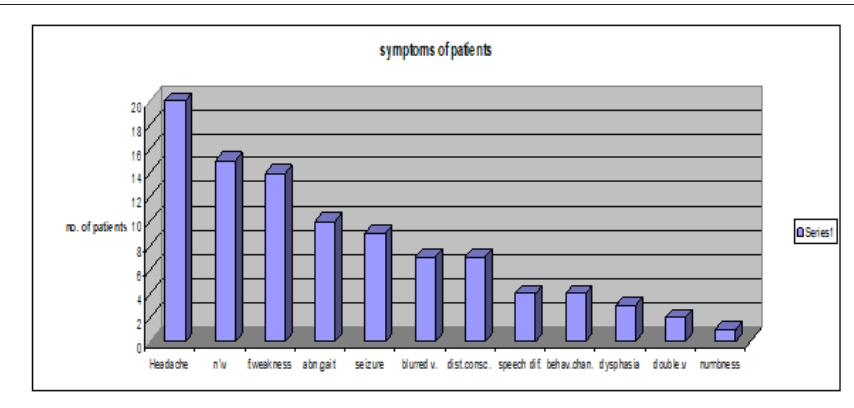

Figure 5: Origin of metastatic tumor.

\section{Headache}

The relation between number of intracranial metastases and the occurrence of headache is shown in $[20,21]$, (Table 6), and indicates that multiplicity does not affect the occurrence of headache.

\begin{tabular}{|c|c|c|c|}
\hline \multicolumn{3}{|c|}{ Table 6: Relation of headache to the multiplicity of brain metastasis. } & Total \\
\hline No. of tumor & Headache & & \\
\hline & Present (\%) & Absent (\%) & 10 \\
\hline Single & $8(80)$ & $2(20)$ & 15 \\
\hline Multiple & $11(73.3)$ & $4(26.6)$ & \\
\hline
\end{tabular}

\section{Blurred vision}

This was recognized in 7 patients (28\%). 5 of them shown to have a clear disc on examination, and 2 of them have papilledema. 4 patients have an occipitoparietal metastases, and 3 [22,23] patients have a posterior fossa metastases.

\section{Past history}

Operation for primary lesion: 15 patients in this study found to have a known primary tumor. Of those, 8 patients had a previous operation for the removal of the tumor from the primary site, (Table 7).

\begin{tabular}{|c|c|c|}
\hline \multicolumn{3}{|c|}{ Table 7: Management of the primary tumor. } \\
\hline Primary site & Surgical treatment & Non Surgical treatment \\
\hline Lung & 2 & 5 \\
\hline Breast & 3 & 2 \\
\hline Bladder & 1 & 0 \\
\hline Lymphatic system & 1 & 0 \\
\hline Colon & 1 & 0 \\
\hline
\end{tabular}

Sign: They are summarized in (Table $8 \&$ Table 9).

CT Scan: This was done for all the patients, 9 of them without I.V contrast, and 16 of them with I.V. contrast enhancement. Ten patients (40\%) have single brain metastases, and 15 patients (60\%) have multiple brain metastases Fig.(3.6) .In the 10 patients having single brain metastasis, the location $[24,25]$ of the metastasis in relation to the brain was shown in (Table 10) and the relation of the primary origin of the tumor to multiplicity is seen in (Table 11). The density of the tumors was variable. 21 patients (84\%) have solid tumors, and 4 patients $(16 \%)$ have a cystic component of the tumor. The density of the solid tumors was isodense in 9 patients, hypodense in 7 patients, mixed density in 2 patients, and hyperdense in 3 patients.

\begin{tabular}{|c|c|c|}
\hline \multicolumn{2}{|l|}{ Table 8: Sign of patients. } \\
\hline Sign & No. & \% \\
\hline Papilledema & 12 & 48 \\
\hline Hemiparesis & 10 & 40 \\
\hline Facial palsy & 5 & 20 \\
\hline Ataxia & 3 & 12 \\
\hline Dysphasia & 2 & 8 \\
\hline 6th nerve palsy & 1 & 4 \\
\hline Visual field defect & 1 & 4 \\
\hline
\end{tabular}

Table 9: Relation of papilledema to the site of cerebral metastasis.

\begin{tabular}{|c|c|c|c|}
\hline Site of tumors & Papilledema & & Total \\
\hline & Present (\%) & Absent (\%) & \\
\hline Supratentorial & $6(35.2)$ & $11(64.7)$ & 17 \\
\hline Infratentorial & $6(75)$ & $2(25)$ & 8 \\
\hline
\end{tabular}

\begin{tabular}{|c|c|c|}
\hline \multicolumn{3}{|c|}{ Table 10: Location of single brain metastasis. } \\
\hline Location & No. & \% \\
\hline Parietal & 3 & 30 \\
\hline Frontoparietal & 2 & 20 \\
\hline Parietooccipital & 2 & 20 \\
\hline $\begin{array}{c}\text { Cerebellum } \\
\text { (hemisphere) }\end{array}$ & 1 & 10 \\
\hline Brain stem & 1 & 10 \\
\hline Frontal & 1 & 10 \\
\hline
\end{tabular}

\begin{tabular}{|c|c|c|c|}
\hline \multicolumn{4}{|c|}{ Table 11: Relation of the site of primary tumor to multiplicity. } \\
\hline $\begin{array}{c}\text { Site of the } \\
\text { primary }\end{array}$ & No. of metastatic lesions & Total \\
\hline Lung & Single & Multiple & \\
\hline Breast & 2 & 5 & 7 \\
\hline Bladder & 4 & 1 & 5 \\
\hline $\begin{array}{c}\text { Lymphatic } \\
\text { system }\end{array}$ & 1 & 0 & 1 \\
\hline Colon & 0 & 0 & 1 \\
\hline Unknown & 3 & 1 & 1 \\
\hline
\end{tabular}

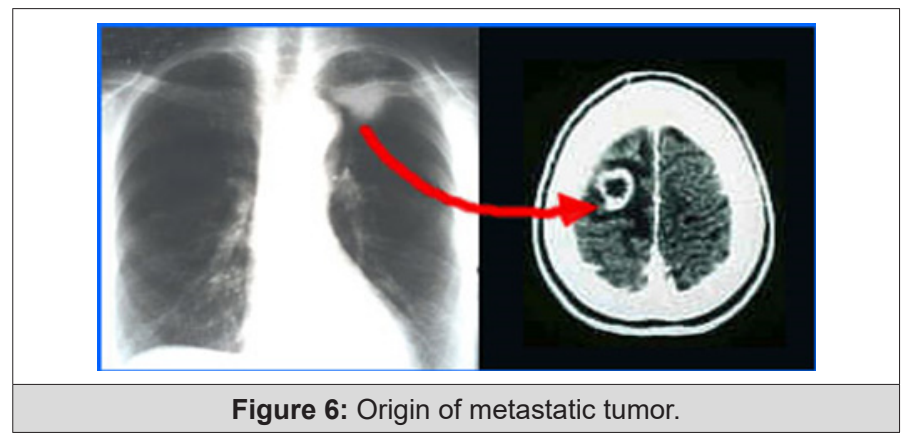

Enhancement of the tumor was seen in all the 16 patients in whom an I. V. contrast was used. 6 patients (37.5\%) showed ring 
like enhancement and 10 patients (62.5\%) showed heterogeneous enhancement.Perifocal edema was noticed in all the cases. It was marked in 6 patients (24\%), moderate in 15 patients (60\%), and mild in 4 patients (16\%). The metastases were supratentorial in 14 patients (56\%), infratentorial in 5 patients (20\%), and both supraand $[26,27,28]$ infratentorial in 6 patients $(24 \%)$. Hydrocephalus was seen in 5 patients (20\%), all of them have an infratentorial brain metastasis. It was due to compression of the 4 thventricle by the metastasis leading to dilatation of the lateral and 3rd ventricles (triventricular hydrocephalus) (Figure 6).

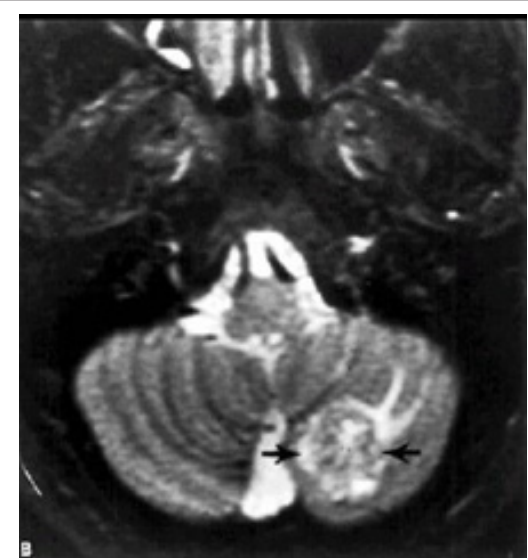

Figure 7: Brain MRI T1 and T2 studies.

MRI: This was done for only 11 cases according the availability of this study in these hospitals.

T1 and T2 studies done for all of those taken the MRI study but Gadolinium contrast study done for only 5 of those cases. (Figure 7 \& Figure 8) Brain MRI T1 and T2 studies.

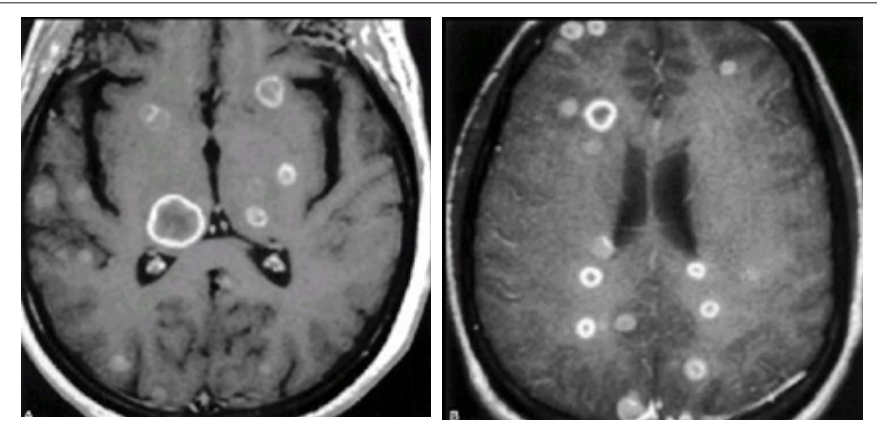

Figure 8: Brain MRI post contrast multiple cystic lesions.

\section{Manegement}

13 patients (52\%) had an operation for the metastatic brain tumor, 6 of them (24\%) had a burr-hole biopsy, and 7 (28\%) had a craniotomy operation or posterior fossa craniectomy. 12 patients (48\%) were refereed for the Institute of Nuclear Medicine to treat them with radiotherapy $[29,30]$ In the 7 patients who had a craniotomy or posterior fossa craniectomy operation, total removal of the metastatic tumor was achieved in 4 patients (57.1\%), subtotal removal in 2 patients (28.5\%) and only a biopsy was taken in the remaining 1 patients $(14.2 \%)$ (Table 12$)$.

\begin{tabular}{|c|c|c|c|c|c|}
\hline Table 12: Management in relation to metastasis multiplicity. \\
\hline \multirow{2}{*}{$\begin{array}{c}\text { Management } \\
\text { No. of tumors }\end{array}$} & $\begin{array}{c}\text { Burgery } \\
\text { Burr hole } \\
(\%)\end{array}$ & $\begin{array}{c}\text { Craniotomy } \\
\& \text { PF } \\
\text { craniectomy }\end{array}$ & $\begin{array}{c}\text { Total } \\
(\%)\end{array}$ & \multicolumn{3}{|c|}{ WBRT } \\
\hline Single & $1(10)$ & $5(50)$ & $6(60)$ & $4(40)$ & 10 \\
\hline Multiple & $5(33.3)$ & $2(13.3)$ & $7(46.6)$ & $8(53.3)$ & 15 \\
\hline
\end{tabular}

\section{Pathological studies}

The specimens taking during the operation of the 13 patients who had operations for the intracranial metastases were preserved in formalin and sent for histological studies to have paraffin sections.

\section{Gross pathology}

The tumor color was grayish-pink in 8 patients and yellowishwhite in 5 patients. The texture was soft in 11 patients and firm in 2 patients. No calcification could be identified in any patient [31,32] Dural attachment of the tumor was noticed in 3 patients, 2 of them were of breast carcinoma origin and 1 patient of unknown primary. The tumor was vascular in 5 patients, and of mild to moderate vascularity in 4 patients. Necrotic tissue was noticed in 6 patients and cystic component of the tumor was aspirated in 7 patients. The fluid was xanthochromic.

\section{Histopathology}

Adenocarcinoma was the diagnosis in 7 patients (53.8\%) of moderate differentiation and show papillary formation in 2 patients $[33,34]$ The histopathological diagnosis in 4 patients $(30.7 \%)$ was undifferentiated carcinoma. Sequamouscell carcinoma was the diagnosis in 2 patients (15.3\%).

\section{Radiotherapy}

12 patients (48\%) who have a histopathological diagnosis of the primary tumor with a clinical and radiological evidence of the metastatic brain tumor were sent for radiotherapy without surgery for the intracranial lesion $[35,36]$.

\section{Discussion}

The Incidence of metastatic brain tumor in our study was $15 \%$ of the total intracranial tumors. This is higher than the incidence in old series that suggest the incidence to be 7-10\% 1,3 , but still lower than the recent studies which revealed that the metastases outnumber all other intracranial tumors combined.24This incidence may be increased in the future in Iraq by the more use of modern neuroimaging techniques (such as availability of MRI) and by more careful autopsy studies on cancer patients.

The Gender distribution shows male preponderance in the incidence of metastatic brain tumors was noticed in this study (male: female ratio 1.5:1) [37,38]. This was also seen in other studies e.g. in Simionescu MD3 (male: female ratio 1.5:1). This is because of the higher frequency of metastases of pulmonary origin 
among males. But still there is increment in the incidence among females because of the increasing incidence of metaslases from breast cancers.

The Age range of our patients in this study lies between 3070 years. If this is compared with Simionescu MD3 study who showed that $75 \%$ of patients lie between $40-60$ years, and the age range was 18-80 years, then we see that the patients in our study are somewhat younger $[39,40]$.This is also seen in recent studies, which showed the age to have a correlation with the incidence of certain cancers.

Presenting symptoms: Headache was the presenting symptoms in $40 \%$ of cases. This is compared with $50 \%$ in other series. 4 It is markedly sever in $50 \%$ of those patients and this could be related to the rapid growth of the metastases. Focal weakness was the presenting symptom in $28 \%$ of the cases, which was usually a localizing sign of the lesion. Most of them responded to medical treatment with steroids, which indicate that it is due to brain edema. $8 \%$ of the cases presented with fit, which was generalized in all of them, and $55.5 \%$ of those patients presented with fit have multiple brain metastases. This shows that the more the number of the intracranial lesions, the more liability of the patient to present with fit. $8 \%$ of the patients have presented with deterioration in the level of $[41,42]$ consciousness that was progressive in $50 \%$ of them and $50 \%$ of them have a single metastatic brain tumor and supratentorial in all of those patients. This may be compared with otherstudies e.g. Simionescu MD3, who record the mental symptoms in $18 \%$ of patients.

The duration of the presenting symptoms was under 1 month, which is regarded to be rapidly progressing, in more than $48 \%$ of our patients in this study which is more than recorded in Simionescu MD3 study who record $18.5 \%$ of patients presented within 1 month [42,43]. This may show the rapid and aggressive growth and behavior of the metastatic brain tumors in this study. In our study the duration of the presenting symptoms in about $76 \%$ of the patients was not more 3 months.

In discussing the interval between the diagnosis of the primary tumors and cerebral metastasis we will compare the results that our study have reached with the results of Simionescu MD3 for each primary origin :

I. For the bronchogenic metastases, this interval is up to 1 year in $71.4 \%$ of our patients, while the same interval is seen in $75 \%$ in the other study.

II. For the metastases of breast origin, the interval was up to 1 year in $60 \%$ of our patient, while the same interval seen in $28.1 \%$ of the patients of the other study.

III. For the metastases of bladder origin, the interval was more than 5 years in the other $100 \%$ of our patients. The other study showed $25 \%$ of the patients to have an interval of 6 months- 1 year.
IV. For the metastases of digestive system origin, the interval was up to 1 year in $100 \%$ of our patients, while was the same in only $33.33 \%$ of the patients in the other study.

In summary this interval in found to be shorter in this study of lung, GIT and longer for breast and bladder than that recorded in Simionescu3 study for all the primary origins. This may show the more aggressive behavior and metastatic tendency of all cancers in our country in the last few years.

The common primary cancer to metastasize to the brain in our study was from the lung and it accounts for $28 \%$ of the patients. This is less than recorded by other studies e.g. 38.1\% in Simionescu study 3, 44\% in the Sloan-Kettering Cancer Center study10, and $45 \%$ in Chevalier TL et al study [44]. The metastases from breast cancers in our study were found in $20 \%$ of the patients and this is comparable with $22.6 \%$ in Simionescu study but is more than the $10 \%$ recorded in the Sloan-Kettering Cancer Center, ] and the $5 \%$ recorded by Chevalier TL et al study.43The metastatic tumors of unknown primary were found in $40 \%$ of our patients which is higher than $11.8 \%$ recorded by the Simionescu study 3 and the $10 \%$ recorded by the Sloan-Kettering Cancer Center.10 This may be due to the rapid metastasis of the primary cancers even with small tumors that can not be detected with the available investigations.

Headache was present in $80 \%$ of the patients in our study that is more than recorded by other studies6,24 which was $50 \%$. Early morning headache was described in only $19 \%$ of the patients, which is less than the $40 \%$ recorded by the Patchell RA study. 22 This may be related to the unawareness of some patients to this character. Our study showed that the incidence of occurrence of headache is the same for the patients with single or multiple brain metastases, $[45,46]$ while Patchell RA et al study showed a higher incidence with multiple brain metastases (44\%) than with single brain metastases (32\%).

Vomiting was recorded in $60 \%$ of the patients and all of them have headache. It was more in patients having multiple brain metastases $(66.6 \%)$ than those with single brain metastasis (33.3\%). [47,48] Focal weakness was present in $48 \%$ of our patients which is comparable to other studies6 that recorded it in $40-60 \%$ of the patients.

Seizures were recorded in $36 \%$ of our patients, which is more than other studies3' 6 that recorded it in $15-25 \%$ of the patients, in our study $2 / 3$ of these patients have multiple brain metastases, and this is also recorded in other studies.

In the past history we found that more than $60 \%$ of the patients with a known. primary tumor had a surgical treatment for this tumor and for those who had nonsurgical treatment $71.4 \%$ of them have a lung tumor. This shows that most of the lung primaries $[49,50]$ are treated nonsurgically. Smoking was recorded in all patients with lung tumor and so can be an important etiological factor.

Papilledema is a sign of raised ICP. This was present in $48 \%$ of 
our patients, which is comparable to the result of the Simionescu study which was $44.6 \%$, but is more than that recorded in other series that show papilledema to occur in $10 \%$ of the patients 6 , and [51] in study which record it to be uncommon. We find in our study that papilledema is more common with single brain metastasis, and with the tumors in the infralentorial regions, while [52,53] in his study3 showed that the number of metastases had no significant effect on the frequency of papilledema.

Motor deficit is an important localizing sign and was recorded in $40 \%$ of our patients which is comparable to other studies recording focal weakness to occur in 40-60\% of their patients. 6 In those cases that motor weakness occurred progressively it was induced by progressive infiltration of the motor cortex or corticospinal tract, and in the other cases that it occurred after fits it was caused by postictal exhaustion.

Ataxia was present in $12 \%$ of our patients, which is less than that recorded in other series that record it in $20 \%$ of the cases.1,6 All of the patients had' an involvement of the cerebellum by metastases.

Dysphasia was present in $8 \%$ of our patients, which is comparable to other studies that record it in $10 \%$ of their patients. It was a good localizing sign in our study.

CT Scan of the brain showed that $60 \%$ of our patients have multiple brain metastases which is comparable to the $51 \%$ recorded by $[54,55]$ study 20 , but is still lower than that recorded by studies that depend on the autopsies of the died cancer patients that record multiplicity in $60-85 \%$ of the patients.24 This percentage will also be higher by the more use of other sophisticated investigations such as the MRI. In comparing the distribution of the metastases in the brain of our study and [56] study we will find the following: Parietal $30 \%$ versus $19 \%$ frontoparietal $20 \%$ versus $7 \%$; parietoccipital $20 \%$ versus $19 \%$, cerebellum $10 \%$ versus $15 \%$.So in this study about $70 \%$ of the metastatic lesions are in and around the parietal lobe compared to $48 \%$ in the study 20 and this is due to the fact that most of the metastatic emboli reach the brain through the middle cerebral artery and its branches. The CT scan results of our study showed that $71.4 \%$ of the metastases from lung origin were multiple, while for the metastases of breast origin $80 \%$ were single.

The same results were obtained by the study but with different percentages in which $54 \%$ of lung metastases were multiple and $68 \%$ of breast metaslascs were single. $61 \%$ of out $\neg$ patients have a supratentorial lesion, which is less than the $80 \%$ recorded by other series. [57] This is because we have included those patients with single metastasis and not those with multiple metastases like the other studies. The infratentorial metastases account for $32 \%$ of the patients, which is comparable to other series 20 that reported it in $15 \%$ of the patients. The other findings of the CT scan were compared to those in study 20 and they were consistent with brain metastases i.e. circumscribed parenchymatous lesion or lesions with a $[58,59]$ cystic component in $16 \%$ of the patients; isodense, hyperdense or hypodense; enhancing after contrast infusion in a heterogeneous fashion (62.5\%) or ring-like enhancement (37.5\%); with mild-severe surrounding edema and edema is more marked with multiple melastases, that cause a mass effect on the adjacent structures and ventricular system causing hydrocephalus in $20 \%$ of the patients[60,61].

In the medical treatment, the steroids were used for all of our patients even for those who had no surgical treatment. Their effect is not only through the reduction of perifocal edema, but also they decrease CSF production, slowing neoplastic growth and may affect neurons directly to improve their function. [62] Most of the clinical features of the patient will be resolved after the use of the steroid. The signs, which persist after steroid therapy, denote a destructive lesion. This predicts a poor chance for improvement of the neurological deficit after surgery. The anticonvulsant medication is used either for those patients with documented fits preoperatively, or as a prophylactic drug i.e. during the perioperative period.

In the surgical treatment, $52 \%$ of our patients were treated surgically for the metastatic brain lesion, which is less than that reported by the study (88.25\%). This shows that in our country the metastatic brain tumors are still regarded of poor prognosis, and most of our surgeons are not exposing such patients to surgery but they usually use other treatment modalities, which is usually radiotherapy. The surgery was done for patients with single brain metastasis (60\%) more frequently than those with multiple brain metastases (46.6\%). The type of surgery was a burr-hole biopsy in $10 \%$ and craniotomy in $50 \%$ of the patients with a single brain metastasis, while for the patients with multiple brain metastases the burr-hole biopsy done in $33.3 \%$ and craniotomy in $13.3 \%$. This in summery shows that the tumor removal by a craniotomy operation is more frequently done with single lesions because it is easier and regarded to be of better prognosis than multiple lesions. Other factors may determine the type of surgery e.g. patient's age, medical illness, and site of the tumor and the ability to diagnose the primary tumor. The burr-hole operation is used to prove the histopathology in patients who are too ill for formal craniotomy, tumors that are suggested to be metastatic with no primary tumor, multiple metastasis, tumor confined to basal ganglia and thalamus, and cystic metastasis to obtain symptoms relief by aspiration of the cyst. The best results with surgery are seen in those patients with a single, surgically accessible lesion and either no remaining systemic disease (true solitary metastasis) or controlled systemic cancer limited to the primary site only.

Radiotherapy is still the treatment of choice for many patients with brain metastasis. In our study $48 \%$ of the patients were sent for radiotherapy depending on the histopathological diagnosis of the primary tumor and the radiological evidence of brain metastasis. In addition, all the patients who had surgery for the intracranial metastasis were also sent for the radiotherapy. So, all 
our patients sent to received radiotherapy. More favorable outcome was associated with:

I. Patient age less than 60 years.

II. Absent or controlled primary tumors.

III. Metastatic spread limited to the brain.

No consensus on radiation dose and treatment schedule has been reached till now. Studies done by the Radiation Therapy Oncology Group showed that there were no significant differences in the frequency or duration of response among conventional daily radiation schedules with total radiation doses ranging from 2000 rad over 1 week to 5000 rad over 4 weeks. Conventional wholebrain radiotherapy is the therapeutic method most commonly employed for patients with brain metastases. The histopathological results of the patients who had an operation for the the intracranial lesions in our study were: Adcnocarcinoma (53.8\%),

undifferentialed carcinoma (30.7\%), and squamous cell carcinoma (15.3\%). These results are somewhat comparable with those of the [63] study of 120 patients in which the histologic diagnosis was obtained in 86 patients $(71.7 \%)$ and the results were: Adenocarcinoma (44.1\%>), undifferentiated or small cell carcinoma (30.3\%), squamous cell carcinoma (11.6\%), indeterminate malignancy (9.2\%), and melanoma (4.6\%).

\section{Conclusion}

Metastatic brain tumors are common in Iraq, but the incidence is still less than reported in the developed countries. It is more common in males. The ages of most of the patients lie between 40-59 years. The duration of the symptoms is less than one month in $48 \%$ of the cases.. The interval between the diagnosis of the primary tumor and the brain metastasis is less than one year in $66.6 \%$ of the patients with known primary, which indicates the aggressive behavior and metastatic tendency of cancers. The most common primary site is the lung, next is the breast, and the third is the bladder.

Forty percent of the patients have unknown primary tumors . Papilledema occurred in $48 \%$ of the patients and was more common with single brain metastasis and with tumors in the infratentorial region.. Metastatic brain tumors are multiple in $60 \%$ and single in $40 \%$ of the cases. $70 \%$ of the metastatic tumors are in and around the parietal lobe of the brain. Most of the metastases from lung origin are multiple (71.4\%), and most of the metastases from breast origin are single (80\%). Clinical improvement is seen after steroid administration in most of the patients. Radiotherapy is still the main treatment modality used for patients with metastatic brain tumors in our country either postoperatively or without surgery. Adenocareinoma is the most common histopathological diagnosis of the brain metastases; next is the undifferentiated carcinoma and the third is sequamous cell carcinoma.

\section{Reference}

1. Young B, Patchell RA (19960 Brain Metastasis, In Youmans JR (ed): Neurological surgery. Philadelphia: WB Saunders, US. PP 2748-2760.

2. Ian E Mc Cutcheon (2005) Metastatic brain tumor. In Setti S Rengachary: Principle of neurosurgery. Mosbey (Edinbergh) Pp. 479-485.

3. Russel DS, Rubinstein LJ (1977) Secondary neoplasms of the nervous system. In Russel DS, Rubinstein LJ: Pathology of tumors of the nervous system, Edward Arnold, USA, pp. 348-360.

4. Simionescu MD (1960) Metastatic tumors of the brain A follow up study of 195 patients with neurosurgical considerations. J Neurosurg; 17: 361-373.

5. Boring CC, Squires TS, Tony T (1993) Cancer statistics. CA Cancer J Clin 43(1): 7-26.

6. Walker AE, Robins M, Weinfield FD (1985) Epidemiology of brain tumors: the national survey of intracranial neoplasm. Neurology 35(2): 219-226.

7. Galicich JH, Arbit E, Wronski M (1996) Metastatic brain tumors. In Wilkins RH, Rengachary SS (eds): Neurosurgery. New York: McGr-aw- HjfcL, US. PP. 807-822.

8. Andrew H Kaye (2006) Essential neurosurgery. Blackwell publishing pp. 80-83.

9. Galicich JH, Sundaresan N, Thaler HT (1980) Surgical treatment of single brain metastasis. Evaluation of results by computed tomography scanning. J Neurosurg 53(1): 63-67.

10. Greenberg MS, (2006) Cerebral metastases In Greenberg MS: Handbook of neurosurgery. Florida: Greenberg Graphics. pp 484-491.

11. Arnold SM, Patchell RA (2001) Diagnosis and management of brain metastases. Hematol Oncol Clin North Am. 15(6): 1085-1107

12. Takakura K, Sano K, Hojo S (1982) Metastatic tumors of the central nervous system. Tokyo: Igaku-shoin.

13. Sawaya R, Ligon BL, Bindal RK (1996) Management of metastatic brain tumors. In Tindall GT, Cooper PR, Barrow DL (eds): The Practice of Neurosurgery. Baltimore: Williams and Wilkins, US. PP. 725-732.

14. Sorensen JB, Ilansen HI I, I Iansen M, Dombernowsky P (1988) Brain metastases in adenocarcinoma of the lung: frequency, risk groups and prognosis. J Clin Oncol 6(9): 1474- 1480.

15. Graus F, Walker RW, Allen JC (1983) Brain metaslases in children. J Pediatr; 103: 558-561.

16. Vannucci RC, Baten M (1974) Cerebral metastatic diseases in childhood. Neurology 24(10): 981-985.

17. Weis L (1996) Factors that govern the metastatic process. In Wilkins RH, Rengachary SS (eds): Neurosurgery. New York: Me Graw- Hill, US. PP.799806.

18. Cairncross JG, Ponser JB (1983) The management of brain metastases. In Walker MD (ed): Oncology of the nervous system. Boston: Martinus Nijhoff, Netherlands Pp. 341-377.

19. Batson OV (1940) The function of the vertebral veins and their role in the spread of metastases. Ann Surg 112(1): 138-149.

20. Delattre JY, Krol G, Thaler HT, Posner JB (1988) Distribution of brain metastases. Arch Neurol 45(7): 741-744.

21. Lavine SD, Petrovich Z, Cohen-Gadol AA, Masri LS, Morton DL, et al. (1999) Gamma Knife radiosurgery for metastatic melanoma. An analysis of survival, outcome and complications. Neurosurgery 44(1): 59-64.

22. Patchell RA (1991) Brain Metastases. Neurol Clin 9: 817-824.

23. KindT GW (1964) The pattern of location of cerebral metastatic tumors. J Neurosurg 21: 54-57. 
24. Pollock BE, Brown PD, Foote RL, Stafford SL, Schomberg PJ (2003) Properly selected patients with multiple brain metastasis may benefit from aggressive treatment of their intracranial disease. J Neuro-Oncol 61(1): 73-80.

25. Sze G, Milano E, Johnson C, Heier L (1990) Detection of brain metastases: Comparison of contrast-enhanced MR with unenhanced MR and enhanced CT. AJNR Am J Neuroradio 1194): 785-791.

26. Young B, Patchell RA (1996) Surgery for a single brain metastasis. In Wilkins RH, Rengachary SS (eds): Neurosurgery. New York: Me Graw-Mill, US. PP. 823-828.

27. Henson R, Urich 11 (1982) Metastases to the brain. In: Cancer and the nervous system. London: Blackwell scientific publication. Pp. 7-58.

28. Stortebecker IP (1954) Metaslatic tumors of the brain from a neurological point of view: A follow up of 158 cases. J Neurosurg 11(1): 84-111.

29. Leavens ML, Moser RP, Obbens LAMT, Iwata KI (1986) Surgical treatment of metastatic brain tumors. Cancer Bull 38: 39-44.

30. Rumana CS, Hess KR, Shi WM, Sawaya R (1998) Metastatic brain tumors with dural extension. J Neurosurg 89(4): 522-558.

31. Ponser JB (1974) Diagnosis and treatment of metastases to the brain. Clinical Bull 4: 47-57.

32. Ponser JB (1980) Clinical manifestations of brain metastases. In Weiss L, Gilbert HA, Ponser JB (eds): Brain Metastases Boston: G K Hall, US. PP. 189207.

33. Patchell RA, Ponser JB (1985) Neurologic complications of systemic cancer. Neurol Clin 3: 729-750.

34. Cohen N, Strauss G, Lew R, Silver D, Recht L (1988) Should prophylactic anticonvulsants be administrated to patients with newly diagnosed cerebral metastases? A retrospective analysis. J Clin Oncol 6(10): 1621-1624

35. Mendez IM, Del Maestro RF (1988) Cerebral metastases from malignant melanoma. Can J Neurol Sci 15: 119-123.

36. Kondziolka D, Bernstein M, Resch L, Tator CH, Fleming JF, et al. (1987) Significance of hemorrhage into brain tumors: clinicopathological study. J Neurosurg 67(6): 852-857.

37. Chiang MF, Brock M, Patt S (1990) pituitary metastases. Neurochirurgia (Stuttg) 33(4): 127-131

38. Morita A, Meyer FB, Laws ER (1998) Symptomatic pituitary metastases. J Neurosurgery 89(1): 69-73.

39. Russel EJ, Geremia GK, Johnson CE, Huckman MS, Ramsey RG, et al (1987) Multiple cerebral metastases: detectable with Gd-DTPA-enhanced MR imaging. Radiology 165(3): 609-617.

40. Sze G, Shin J, Krol G, Johnson C, Liu D, et al. (1988) Intraparanchymal brain metastases: M.R. imaging versus contrast-enhanced CT. Radiology 168(1): 187-194.

41. Little JR, Frankel A (1996) Meningeal carcinomatosis. In: Wilkins RH, Rengachary SS (Eds.), Neurosurgery, New York: Me Graw- Hill, US. pp. 829-832.

42. Sze G, Soltsky S, Bronen R, Krol G (1989) MR imaging of the cranial meninges with emphasis on contrast enhancement and meningeal carcinomatosis. AJNR Am J Neuroradiol 10(5): 965-975.

43. Chevalier TL, Smith FP, Caille P, Constans JP, Rouesse JG (1985) Sites of Primary malignancies in patients presenting with cerebral metastases. A review of 120 cases. Cancer 56(4): 880-882.
44. Knuckey NW, Stoll J, Epstein MIL (1989) Intracranial and spinal meningiomas in patients with breast carcinoma: case reports. Neurosurgery 25: $112-117$

45. Senegor M (1991) Prominent meningeal "tail sign" in a patient with metaslatic tumor. Neurosurgery 29(2): 294-296.

46. Umezu H, Sano T, Aiba T, Unakami M (1994) Calcified intracranial metastatic tumor mimicking meningioma--case report. Neurol Med Chir Tokyo 34(2): 108-110.

47. Furui T, Ichihara K, Ikeda A, Inao S, Hirai N, et al. (1983) Subdural hematoma associated with disseminated intravascular coagulation in patients with advanced cancer. J Neurosurgery 58(3): 398-401.

48. Markesbery WR, Brooks WLI, Gupta GD, Young AB (1978) Treatment of patients with cerebral metastases. Arch Neurol 35(11): 754-756.

49. Chao JH, Phillips R, Nickson JJ (1954) Roentgen-ray therapy of cerebral metastases. Cancer 7(4): 682-689.

50. Evre HJ, Ohlsen ID, Frank J, LoBuglio AF, McCracken JD, et al. (1984) Randomized trial of radiotherapy versus radiotherapy plus metronidazole for the treatment of metaslatic cancer to the brain: A Southwest Oncology Group study. J Neurooncol 2(4): 325-330.

51. De Angelis LM, Delattre J Y, Ponser IB (1989) Radiation induced dementia in patients cured of brain metastases. Neurology 39(6): 789-796.

52. Sawaya R, Ligon BL, Bindal AK, Bindal RK, Hess KR (1996) Surgical treatment of metastatic brain tumors. J Neurooncol 27(3): 269-277.

53.Sundaresan N, Galicich JH, Beattie EJ (1983) Surgical treatment of brain metastases from lung cancer. J Neurosurg 58(5): 666-671.

54. Bindal RK, Sawaya R, Leavens ME, Lee JJ (1993) Surgical treatment of multiple brain metastases. J Neurosurg 79(2): 210-216.

55. Lang FF, Sawaya R (1998) Surgical treatment of metastatic brain tumors. Seminars in Surgical Oncology 14: 53-63.

56. Bindal AK, Bindal RK, Hess KR, Shiu A, Hassenbusch SJ, et al. (1996) Surgery versus radiosurgery in the treatment of brain metastasis. J Neurosurg 84(5): 748-754.

57. Alexander E, Moriarty TM, Davis RB, Wen PY, Fine HA, et al. (1995) Stereotactic radiosurgery for the definitive, noninvasive treatment of brain metastases. J Natl Cancer Inst 87(1): 34-40.

58. Matsumoto K, Tada E, Tamesa N, Tomita S, Ohmoto T (1998) Stereotactic brachytherapy for a cystic metastatic brain tumor in the midbrain. Case report. J Neurosurg 88(1): 141-144.

59. Bindal RK, Sawaya R, Leavens ME, Hess KR, Taylor SH (1995) Reoperation for current metastatic brain tumors. J Neurosurg 83(4): 600-604.

60. Wronski M, Arbit E, Burt M, Galicich JH (1995) Survival after surgical treatment of brain metastases from lung cancer. A follow-up study of 231 patients treated between 1976 and 1991. Neurosurg 83(4): 605-616.

61. Sampson JH, Carter JH, Friedman AH, Seigler HF (1998) Demographics, prognosis, and therapy in 702 patients with brain metastases from malignant melanoma. J Neurosurg 88(1): 11-20.

62.0jeman GA (1979) Pathophysiologic basis of posterior fossa tumor signs and symptoms. In: Bucheit WA, Truex RC (Eds.), Surgery of the posterior fossa Raven press, Greece, pp. 37-56.

63. Ningaraj NS, Rao M, Hashizume K, Asotra K, Black KL (2002) Regulation of blood-brain tumor barrier permeability by calcium-activated potassium channels. J Pharmacol Exp Ther 301(3): 838-851. 